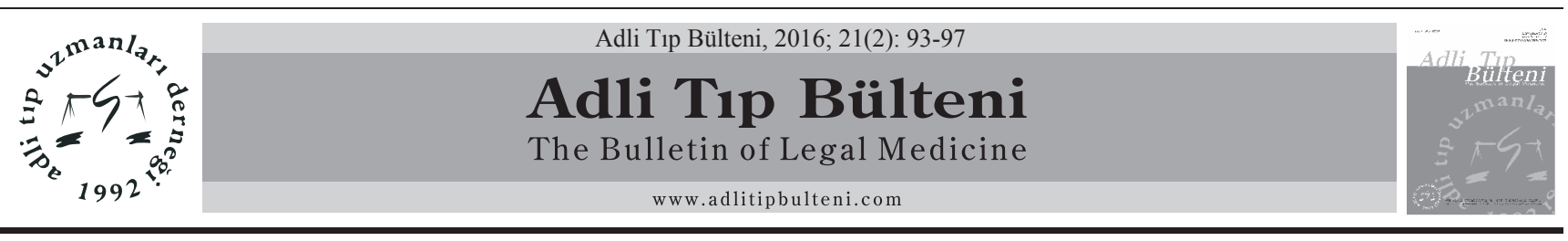

\title{
Samsun'da Erken Çocukluk Çağı Zehirlenmeleri 2010-2015
}

\author{
Early Childhood Poisonings in Samsun 2010-2015
}

\author{
Salih Tunahan Polat, Serkan Çăglayan, Ahmet Turla, Berna Aydın
}

Ondokuz Mayıs Üniversitesi, Tıp Fakültesi Adli Tıp Anabilim Dalı, Samsun

\section{Özet}

Amaç: Bu çalışma, Ondokuz Mayıs Üniversitesi Sağlık Uygulama ve Araştırma Merkezine zehirlenme nedeniyle getirilen erken çocukluk yaş grubundaki (1-4 yaş) olguların değerlendirilmesi ve elde edilen bulguların koruyucu önlemlerin alınmasında yol gösterici olması amacıyla yapılmıştır.

Gereç ve Yöntem: 01 Ağustos 2010 - 31 Temmuz 2015 tarihleri arasındaki beş yıllık süre içerisinde zehirlenme nedeniyle Ondokuz Mayıs Üniversitesi Sağlık Uygulama ve Araştırma Merkezine getirilen 1-4 yaş aralığındaki 761 çocuk çalışmaya dahil edilmiştir. Kesitsel nitelikteki bu çalışmada elde edilen veriler SPSS istatistik programı kullanılarak değerlendirilmiştir.

Bulgular: Olguların 413 (\%54,3)'ü erkek, $348(\% 45,7)$ 'i kadındır. En fazla olgu; Temmuz $(\% 11,8)$ ve Mayıs $(\% 11,6)$ ayında, Pazartesi günleri $(\% 18,3)$ ve saat $16.00-23.59$ arasında başvurmuştur. Çocuklar istatistiksel olarak anlamlı bir şekilde en çok ilaç $(\% 48,3)$ ile zehirlenmiștir.

Sonuç: Erken çocukluk yaş grubunda ev içinde meydana gelebilecek zehirlenmelere karşı ebeveynlere ya da çocuğa bakım verenlere yönelik yapılacak eğitim çalışmaları oldukça önemlidir. Bunun yanı sıra hastaların zehire daha kısa süre maruz kalması açısından acil servislerde insan gücü planlaması başvuru zamanları gözetilerek düzenlenmelidir.

Anahtar Kelimeler: Çocukluk çağı; Zehirlenme; Kaza; Acil Servis; Önleme.

\section{Giriş}

Acil servis başvurularının önemli bir kısmını oluşturan zehirlenmeler kazara veya özkıyım amaçlı olarak oral alım ya da inhalasyon yolu ile ilaç ya da diğer kimyasal maddelerin alınmasıyla gerçekleşir. Ülkemizde yapılan epidemiyolojik çalışmalar, tüm acil servis başvurularının \%0,7-5,0'ini zehirlenme olgularının oluşturduğunu göstermektedir (1-5).

Sorumlu Yazar: Prof.Dr.Berna Aydin

Ondokuz Mayıs Üniversitesi Tip Fakültesi,

Adli Tıp Anabilim Dalı, Kurupelit Kampüsü, Samsun

E-mail:baydin@omu.edu.tr

Geliş: 01.04.2016 Düzeltme: 17.05.2016 Kabul: 06.06.2016

\section{Abstract}

Objective: The purpose of this study was to assess cases in early childhood age group (1-4 years of age) who were admitted to Ondokuz Mayis University Health Application and Research Center due to poisoning and to obtain guiding results in taking protective measures.

Materials and Methods: 761 children between the ages of 1 to 4 who were admitted to Ondokuz Mayis University Health Application and Research Center between 01 August 2010 and 31 July 2015 with a diagnosis of poisoning were included in the study.

The data obtained with this cross sectional study was analyzed by using SPSS statistic program.

Results: $413(54,3 \%)$ of the cases were male, while 348 $(45,7 \%)$ were female. The highest number of cases were admitted in the months of July $(11,8 \%)$ and May $(11,6 \%)$, on Mondays $(18,3 \%)$ and between the hours $16.00-23.59$. Drugs were statistically significantly the most common reason $(48,3 \%)$ for poisoning in children.

Conclusion: In early childhood age group, trainings for parents or caregivers against poisoning that may happen in the house are quite important. In addition, labor force planning should be arranged by considering admission times in emergency services to make sure that patients are exposed to poison for a shorter period of time.

Keywords: Childhood; Poisoning; Accident; Emergency; Department; Prevention.

Toksine maruziyet; çevresel olarak, kazayla, tedavi sırasında ya da kasıtlı olarak gerçekleşebilir. Toksik maddelerin vücuda alınma yolu, toksik maddenin cinsi ve ortaya çıkan belirtiler erişkinlerde ve çocuklarda farklılık gösterebilmektedir. Çocukluk çağında zehirlenmeler genellikle ev temizlik ürünleri ve ilaçlar ile kaza sonucu meydana gelirken, erişkinlerde zehirlenmeler daha çok bazı ilaçlarla kasıtlı olarak gerçekleşmektedir $(6,7)$.

Çocukluk çağında görülen kazara olan zehirlenmeler halen önemli bir halk sağlığı sorunudur. Çocuklarda 1-5 yaş aralığında en sık görülen akut zehirlenme olguları tüm çocukluk çağı zehirlenmelerinin \%80'ini oluşturmaktadır (8-10). Zehirlenme nedenleri sıklıkla ilaçlar (reçeteli-reçetesiz), ev temizlik ürünleri, parafin-gazyağ $\breve{1}_{\text {, }}$ 
pestisitler, zehirli bitkiler ve hayvan ya da böcek 1sırmalarıdır (11-13).

Bu çalışma, Ondokuz Mayıs Üniversitesi Sağlık Uygulama ve Araştırma Merkezine zehirlenme nedeniyle başvuran erken çocukluk yaş grubundaki (1-4 yaş) olguların değerlendirilmesi ve elde edilen bulguların koruyucu önlemlerin alınmasında yol gösterici olması amacıyla yapılmıştır.

\section{Gereç ve Yöntem}

01 Ağustos 2010-31 Temmuz 2015 tarihleri arasındaki beş yıllık süre içerisinde zehirlenme tanısıyla Ondokuz Mayıs Üniversitesi Sağlık Uygulama ve Araştırma Merkezine getirilen 1-4 yaş aralığındaki 761 çocuk olgu çalışmamıza dâhil edilmiştir.

Kesitsel nitelikteki çalışmamızda olguların hasta adli dosyaları incelenerek; cinsiyet, yaş, başvuru zamanı, zehirlenme etkenleri, tedavi şekilleri (ayaktan, serviste yatış, yoğun bakım) araştırılmıştır.

Zehirlenme etkenleri; tıbbi ilaçlar, koroziv maddeler, kimyasal maddeler (tiner, naftalin, petrol ve türevleri vs.), gıda maddeleri, karbonmonoksit, tarım ilacı, fare zehiri ve böcek ilacı, sıvı temizlik maddeleri, alkol ve bileşikleri, zehirli ot ve bitki olarak gruplandırılmıştır. Hastaneye başvuru zamanı ay, gün ve saat olarak (00.00'dan başlayarak sekizer saatlik dilimler halinde) düzenlenmiştir.

Elde edilen veriler SPSS istatistik programı (Version15.0, SPSS Inc., Chicago, Illinois) ile değerlendirilmiştir. Gruplar arasındaki karşılaştırmalarda ki-kare testi kullanılmış, anlamlılık değeri $\mathrm{p}<0,05$ olarak kabul edilmiştir.

\section{Bulgular}

Ondokuz Mayıs Üniversitesi Sağlık Uygulama ve Araştırma Merkezi'ne 01.08.2010-31.07.2015 tarihleri arasında getirilen 19.122 adli olgudan $5124(\% 26,8)$ 'ü zehirlenme olguları olup bunların da $761(\% 14,9)$ 'i 1-4 yaş aralığında çocuklardır. 1-4 yaş grubundaki zehirlenme olgularının $413(\% 54,3)$ 'ü erkek, $348(\% 45,7)$ 'i kadindir.

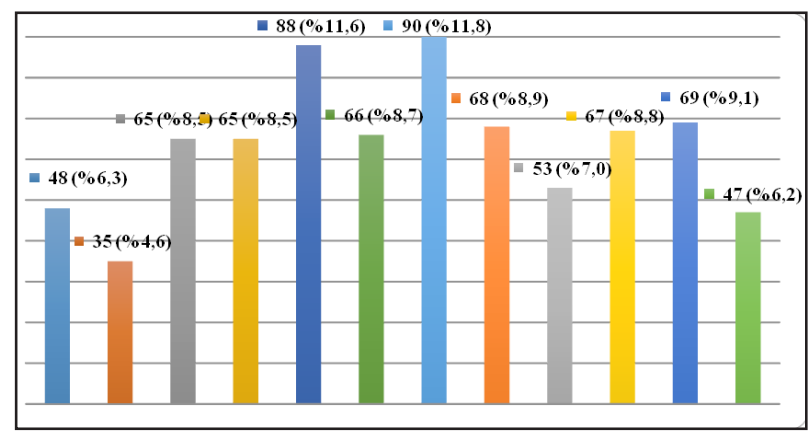

Grafik 1. Olguların Hastaneye Başvurduğu Ayların Dağılımı.

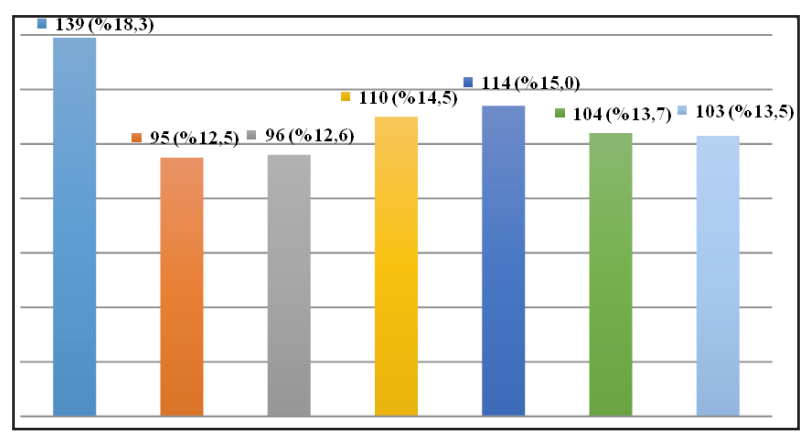

Grafik 2. Olguların Hastaneye Başvurduğu Günlerin Dağ 1 lımı.

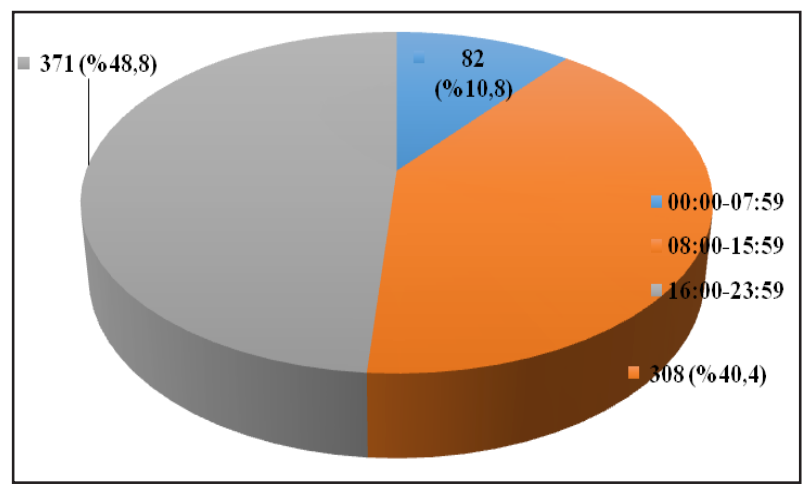

Grafik 3. Olguların Hastaneye Başvurduğu Saatlerin Dağılımı.

En fazla olgu; Temmuz $(\% 11,8)$ ve Mayıs $(\% 11,6)$ ayında, Pazartesi günleri $(\% 18,3)$ ve saat $16.00-23.59$ $(\% 53,6)$ arasında başvurmuştur. Olguların hastaneye başvurduğu ay, gün ve saatler Grafik 1-3’te gösterilmiştir.

Çocuklar istatistiksel olarak anlamlı bir şekilde en çok ilaç $(\% 48,3)$ ile zehirlenmiş olup bunu koroziv madde $(\% 17,1)$ ve fare zehiri-böcek ilacı $(\% 12,0)$ ile diğer zehirlenmelerin izlediği görülmüştür. Yaş gruplarına göre zehirlenmeye neden olan maddelerin dağılımı Tablo 1'de gösterilmiştir.

Zehirlenen çocukların $\% 69,1$ 'i ayaktan tedavi edilerek evine gönderilmiş olup $\% 1,8$ 'i yoğun bakım ünitesinde yatarak tedavi edilmiştir. Tüm olgular tedavi sonrası şifa ile taburcu olmuştur.

\section{Tartıșma}

Adli nitelikteki olayların soruşturulması ve kovuşturulması aşamasında olguların muayenesi ve adli raporlarının düzenlenmesi büyük önem taşımakta ve adli süreçte yol gösterici olmaktadır. Adli olaylar içerisinde yer alan zehirlenme olguları hekimlerin özellikle acil uygulamalarında sık karşılaştığı olgulardır. Çocukluk çağı zehirlenmeleri içerisinde önemli bir yer tutan erken çocukluk dönemi zehirlenmeleri; çocukların yürümeye başladıkları 
Tablo 1: Yaş gruplarına göre zehirlenmeye neden olan maddelerin dağılımı.

\begin{tabular}{|c|c|c|c|c|c|c|c|c|}
\hline \multirow{3}{*}{ Tanı } & \multicolumn{6}{|c|}{ Yaş grupları } & \multirow{2}{*}{\multicolumn{2}{|c|}{ Toplam }} \\
\hline & \multicolumn{2}{|c|}{$12-23$ ay } & \multicolumn{2}{|c|}{ 24-35 ay } & \multicolumn{2}{|c|}{$36-47$ ay } & & \\
\hline & n & $\%$ & $\mathbf{n}$ & $\%$ & $\mathbf{n}$ & $\%$ & $\mathbf{n}$ & $\%$ \\
\hline İlaç & 99 & 37,4 & 163 & 52,2 & 106 & 57,6 & 368 & 48,3 \\
\hline Koroziv madde & 67 & 25,3 & 39 & 12,5 & 24 & 13,1 & 130 & 17,1 \\
\hline Kimyasal madde* & 21 & 7,9 & 33 & 10,6 & 18 & 9,8 & 72 & 9,5 \\
\hline G1da maddesi & 3 & 1,1 & 2 & 0,6 & 4 & 2,2 & 9 & 1,2 \\
\hline Karbonmonoksit & 4 & 1,5 & 9 & 2,9 & 5 & 2,7 & 18 & 2,4 \\
\hline Tarım ilacı & 6 & 2,3 & 9 & 2,9 & 8 & 4,4 & 23 & 3,0 \\
\hline Sivi temizlik maddesi & 15 & 5,7 & 9 & 2,9 & 5 & 2,7 & 29 & 3,8 \\
\hline Fare zehiri-böcek ilacı & 42 & 15,8 & 39 & 12,5 & 10 & 5,4 & 91 & 12,0 \\
\hline Zehirli ot ve bitki & 1 & 0,4 & 3 & 1,0 & 1 & 0,5 & 5 & 0,6 \\
\hline Alkol ve bileşikleri & 7 & 2,6 & 6 & 1,9 & 3 & 1,6 & 16 & 2,1 \\
\hline Toplam & 265 & 100,0 & 312 & 100,0 & 184 & 100,0 & 761 & 100,0 \\
\hline
\end{tabular}

*tiner, naftalin, petrol ve türevleri vs., $x 2=48,19 p=0,000$

bu yaş grubunun yeni nesnelere daha meraklı olma, renkli objeleri ağızlarına götürme ve ebeveynlerini taklit etme eğilimi gibi özelliklerinden kaynaklanmaktadır (14).

Ondokuz Mayıs Üniversitesi Sağlik Uygulama ve Araştırma Merkezi'ne 5 yıllık süre içerisinde gelen/getirilen 19.122 adli olgudan $5.124(\% 26,8)$ 'ü zehirlenme olguları olup bunların da 761 (\%14,9)'i 1-4 yaş aralığındadır. Bu konuda yapılan başkaca çalışmalarda acil servise başvuran zehirlenme olgularının oranları $\% 0,6-33,8$ aralığında değişmektedir (10,15-20). Hem ülkemizde hem de yurtdışında yapılan bu çalışmaların sonuçları oldukça geniş bir aralık içerisinde yer almaktadır. Bu durumun her merkeze başvuran genel olgu sayılarındaki ve türlerindeki farklılıklardan, çalışmaya konu olan yaş gruplarındaki farklılıklarından, çalışma yapılan yerlerin yerel özelliği gibi durumlardan kaynaklandığı görülmektedir. Zehirlenme türleri değişik ülkelerde, hatta aynı ülkenin değişik bölgelerinde farklılıklar göstermektedir. Bu nedenle her ülke kendi zehirlenme profilini belirlemeli ve bu göre önlemler almalıdır.

Olguların 413 (\%54,3)'ü erkek, 348 (\%45,7)'i kadındır. Bu oran, konu ile ilgili benzer çalışmalarla uyumludur (12,21-24). Aynı zamanda 2014 TÜİK (Türkiye İstatistik Kurumu) verilerindeki 0-4 yaş aralığındaki cinsiyet oranları ile de benzeşmektedir (25). Bu nedenle zehirlenen 1-4 yaş grubu çocuklarda cinsiyetle ilişkisi olmadığını söylemek mümkündür. Ancak kız çocuklarında zehirlenmelerin daha fazla olduğunu bildiren çalışmalar da mevcuttur $(15,17)$.

Çalı̧̧mamıza konu olan 1-4 yaş grubu çocuk olgular; en fazla Temmuz $(\% 11,8)$ ve Mayıs $(\% 11,6)$ ayında, Pazartesi günleri $(\% 18,3)$ ve saat $16.00-23.59$ arasinda
$(\% 48,8)$ hastaneye getirilmiştir (Grafik 1-3). Öz ve arkadaşlarının (17) Eskişehir'de yaptıkları ve tüm yaş gruplarını kapsayan zehirlenmelerle ilgili çalışmalarında; en sık başvuru gününün Pazar $(\% 18,6)$, başvuru saatinin de 16.00-24.00 olduğu saptanmıştır. Türkçüer ve ark.nın (26) Denizli'de yaptıkları çalışmada; adli olguların acil servise en fazla Temmuz ayında $(\% 13,4)$, Pazartesi günleri $(\% 15,6)$ ve saat $22.00-24.00(\% 17,5)$ arasında başvurduğu, Deniz ve ark.nın (15) çalışmasında da; zehirlenme nedeniyle hastaneye başvuru saatinin $\% 55,6$ olguda 16.00-24.00 saatleri arasında olduğu bildirilmektedir. Tüm adli olgularda olduğu gibi zehirlenme olgularında da yaz aylarında görülen artışı gündüz saatlerinin uzamas1 ve insanların aktivitelerinde artış olması ile açıklamak mümkündür. Aynı zamanda bu aylar tarımsal faaliyetlerin arttığı, tarımsal ilaçların ortamda daha fazla bulunduğu dönemdir. Başvuru saatlerine bakıldığında çalışmamızla da uyumlu olarak hemen hemen tüm çalışmalarda yoğunluğun 16.00 - 23.59 saatleri arasında olması zehirlenme etkenlerinin ev ortamı içerisinde olması göz önüne alındığında, evde bulunulan saatlerde daha sik zehirlenme olması ile uygunluk göstermektedir.

Çocuklar istatistiksel olarak anlamlı bir şekilde en çok ilaç $(\% 48,3)$ ile zehirlenmiş olup bunu koroziv madde $(\% 17,1)$ ve fare zehiri-böcek ilac1 $(\% 12,0)$ ile diğer zehirlenmelerin izlediği görülmüştür (Tablo 1). Yurtiçi ve yurtdışında bu konuda yapılan benzer birçok çalışmanın ortak verisi bu yaş grubunda ilaçların en sık görülen zehirleyici ajan olduğudur $(15,17,21,27)$. Ankara'da yapılan bir çalışmada (27); ilaçla zehirlenen çocukların \%93,3'ünün ev içinde mevcut bir ilaçla zehirlendiğini, en s1k $(\% 23,7)$ zehirlenmeye neden olan ilaç türünün de 
analjezikler olduğu, Repetto'nun (28) İspanya'da yaptığı çalışmada merkezi sinir sistemine etkili ilaçların ve analjeziklerin çocukluk çağı zehirlenmelerinde önemli yer tuttuğu, Kuveyt'te yapılan bir çalışmada da (21); benzer olarak analjezik-antipiretik ilaçların $(\% 36,9)$ zehirlenmeye neden olduğu bildirilmektedir. Paracetamol türü ilaçlar çoğu çalışmada ilk sırada yer almaktadır $(28,29)$. Çalışma grubundaki olguların tıbbi kayıtlarında zehirlenmeye neden olan ilaç isimleri çoğunlukla hatalı kaydedilmiş ya da hiç yazılmamış olduğundan bilimsel nitelikte sonuç çıkartılamayacağı düşünülerek değerlendirmeye alınmamıştır.

İlaç üretim ve tüketiminin her yıl giderek büyük hacimlere ulaşması, beraberinde özellikle evlerde kullanım dışı kalmış ilaçların miktarını da artırmaktadır. Çocuklu ailelerde bu durum daha tehlikeli olup bu ilaçlar potansiyel zehirlenme riski taşımaktadır. Evlerde bulunan aile bireylerinin kullandığı ya da kullanım dışı kalmış ilaçlarla oluşan zehirlenmeler ile ilgili yapılan araştırmalarda en çok ölümün çocukluk çağında olduğu akıldan çıkartılmamalıdır (30-32).

Çocuklar kendilerini kazalardan koruyamadıklarından, kazalar açısından emniyetli ortamlarda yaşamala$\mathrm{r} 1$, koruyucu önlemlerin alınması ve yaşam alanlarının güvenliğinin denetlenmesi erişkinlerin sorumluluğudur (33). Erken çocukluk yaş grubunda ev içinde meydana gelebilecek zehirlenmelere karşı ebeveynlere ya da çocuğa bakım verenlere yönelik yapılacak eğitim programları ve sosyal çalışmalar ile bu tip kazalar azaltılabilir (24). Çocukları zehirlenme etkenlerinden korumanın pek çok yöntemi vardır. Zehirlenme olaylarının yaşanmaması için ilaçların veya zehirlenme etkenlerinin saklaması ve korunması konusunda, zehirleyici ajana maruz kalma sonras1 ise çıkabilecek bulgular, acil olarak yapılacaklar, zehrin yutulması durumunda absorbsiyonu en aza indirgeyecek ve zehiri nötralize edecek uygulamalar konusunda çocuklara bakım verenler mutlaka eğitilmelidir (34).

Zehirlenme olgularında hızlı davranmak çoğu zaman hayat kurtarıcıdır. Çalışmalar ışığında; olguların mevsimsel, haftanın günlerine ve gün içerisinde başvuru saat dilimlerine göre dağılımı göz önüne alınarak hastaların zehire daha kısa süre maruz kalması açısından acil servislerde insan gücü planlaması yapılmalıdır.

\section{Kaynaklar}

1. Mert E, Bilgin NG. Demographical, etiological and clinical characteristics of poisonings in Mersin, Turkey. Hum Exp Toxicol. 2006;25(4):217-23. doi: 10.1191/0960327106ht612oa

2. Özköse Z, Ayoglu F. Etiological and demographical characteristics of acute adult poisoning in Ankara, Turkey. Hum Exp Toxicol. 1999;18:614-8.
3. Akköse Ş, Fedakar R, Bulut M, Çebiçci H. Zehirlenme Olgularının Beş Yıllık Analizi. Türkiye Acil Tıp Dergisi. 2003;3:8-10.

4. Pinar A, Fowler J, Bond GR. Acute poisoning in Izmir, Turkey- A pilot epidemiologic study. J Toxicol Clin Toxicol. 1993;31:593-601. DOI:10.3109/15563659309025764

5. Karakaya A, Vural N. Acute poisoning admissions in one of the hospitals in Ankara. Hum Toxicol. 1985;4:323-6.

6. Ellenhorn MJ. Ellenhorn's Medical Toxicology: Diagnosis and Treatment of Human Poisoning. 2nd ed. Williams \& Wilkins;1997:1-46.

7. Yeşil O, Akoğlu H, Onur O, Güneysel O. Acil servise başvuran zehirlenme olgularının geriye dönük analizi. Marmara Medical Journal. 2008;21:26-32.

8. Petridou E, Kouri N, Ploychronopoulou A, Siafas K, Stoikidou M, Trichopoulos D. Risk factors for childhood poisoning: a case control study in Greece. Inj Prv 1996;2(3):208-11.

9. Mutlu M, Cansu A, Karakas T, Kalyoncu M, Erduran E. Pattern of pediatric poisoning in the east Karadeniz region between 2002-2006: increased suicide poisoning. Hum Exp Toxicol. 2010;29(2):131-6. doi: $10.1177 / 0960327109357141$

10. Agarwal V, Gupta A. Accidental poisoning in children. Indian Pediatr. 1984;11(9): 617-21.

11. Lam LT. Childhood and adolescence poisoning in NSW, Australia: an analysis of age, sex, geographic, and poison types. Inj Prev. 2003;9:338-42. doi:10.1136/ip.9.4.338

12. Keka A, Ramosaj A, Toro H, Azemi M, Baloku A, Sylaj B, et al. Acute poisoning in children; changes over the years, data of pediatric clinic department of toxicology. J Acute Disease. 2014:56-8. doi: 10.1016/S2221-6189(14)60012-3

13. Budnitz DS, Lovegrove MC. The last mile: taking the final steps in preventing pediatric pharmaceutical poisonings. $\mathrm{J}$ Pediatr. 2012;160(2):190-2. doi: 10.1016/j.jpeds.2011.09.020

14. Oliveira FF, Suchara EA. Epidemiological profile of exogenous poisoning in children and adolescents from a municipality in the state of Mato Gross. Rev Paul Pediatr. 2014;32(4):299-305. doi: 10.1016/j.rpped.2014.06.002

15. Deniz T, Kandiş H, Saygun M, Büyükkoçak Ü, Ülger H, Karakuş A. Kırıkkale Üniversitesi Tıp Fakültesi Acil Servisine Başvuran Zehirlenme Olgularının Analizi. Düzce Tip Fakültesi Dergisi. 2009;11(2):15-20.

16. Marahatta S, Singh J, Shrestha R, Koju R. Poisoning cases attending emergency department in Dhulikhel HospitalKathmandu University Teaching Hospital. Kathmandu University Medical Journal. 2010;7(2):152-56 doi: 10.3126/ kumj.v7i2.2711.

17. Öz F, Çevik AA, Gökler ME, Ünsal A. Bir Üniversite Hastanesinin Acil Servisine Zehirlenme Nedeniyle Yapılan Başvuruların Değerlendirilmesi. STED. 2013;21(1):343-9.

18. Kocakaya M, Aydın B, Turla A, Özkanlı C. OMÜ Tıp Fakültesi Sağlık Uygulama ve Araştırma Merkezine gelen karbonmonoksit zehirlenmesi olgular1-2004. Solunum. 2007;1:11-6.

19. Reith DM, Pitt WR, Hockey R. Childhood poisoning in Queensland: an analysis of presentation and admission rates. J Peadiatr Child Health. 2001;37:446-50.

20. Kukul FM, Bütün C, Beyaztaş FY, Eren ŞH, Korkmaz İ. Cumhuriyet Üniversitesi Tip Fakültesi Hastanesine 
Başvuran Adli Olguların Değerlendirilmesi. ADÜ Tıp Fakültesi Dergisi. 2009;10(3):23-8.

21. Ahmed A, Al Jamal AN, Ibrahim MIM, Salameh K, Al Yafei K, Abu Zaineh S, et al. Poisoning emergency visits among children: a 3-year retrospective study in Qatar, BMC Pediatrics. 2015;15:104-7. doi: 10.1186/s12887-015-0423-7

22. Karadeniz H, Birincioğlu İ, Turna Ö, Ketenci HÇ, Beyhun NE. Fatal poisoning of chilhood in the Eastern Black Sea region of Turkey (2009-2013). J Forensic Legal Med. 2015;34:109-12. doi: 10.1016/j.jflm.2015.06.001

23. Rama P, Kanchan T, Unnikrishnan B. Pattern of acute poisonings in children below 15 years - A study from Mangalore, South India. J Forensic Legal Med. 2014;25:269. doi: 10.1016/j.jflm.2014.04.001

24. Manouchehrifar M, Derakhshandeh N, Shojaee M, Sabzghabaei A, Farnaghi F. An Epidemiologic Study of Pediatric Poisoning; a Six-month Cross- sectional Study. Emerg (Tehran). 2016;4(1):21-4.

25. "TUIK, İl yaş grubu ve cinsiyete göre nüfus - 2014, Türkiye" [Internet]. [cited 2015 Nov 19]. Available from: http://rapory.tuik.gov.tr

26. Türkçüer İ, Gözlükaya A, Serinken M, Özen M, Aydın B. Adli Olguların Acil Servise Başvuru Zamanları. Akademik Acil Tip Dergisi. 2010;2:89-92.

27. Andiran N, Sarıkayalar F. Pattern of acute poisonings in childhood in Ankara: what has changed in twenty years? Turk J Pediatr. 2004;46(2):147-52.
28. Repetto MR., Epidemiology of poisoning due to pharmaceutical products, Poison Control Centre, Seville, Spain., Eur J Epidemiol. 1997;13(3):353-6.

29. Koliou M, Ioannou C, Andreou K, Petridou A, Soteriades ES. The epidemiology of childhood poisonings in Cyprus. Eur J Pediatr. 2010;169(7):833-8 doi: 10.1007/s00431-009-1124-8.

30. De Bolle L, Mehuys E, Adriaens E, Remon JP, Van Bortel L, Christiaens T. Home medication cabinets and selfmedication: a source of potential health threats? Ann Pharmacother. 2008;42(4):572-9. doi: 10.1345/aph.1K533.

31. Ruhoy IS, Daughton CG. Beyond the medicine cabinet: An analysis of where and why medications accumulate. Environ Int. 2008;34:1157-69. doi: 10.1016/j.envint.2008.05.002

32. Köse G, Battal D, Aktaş A, Saygı Ş. Evlerde bulunan kullanım dışı ilaçlarla ilgili toplum farkındalığının araștırılması: bir pilot çalışma Marmara Pharmaceutical J. 2013;17:155-9.

33. Ulukol B, Şimşek F, Usubütün S, Gülnar S. 0-6 Yaş grubu çocukların ev kazalarından korunmasında anne eğitiminin etkinliği. III. Ulusal Ana Çocuk Sağlığı Kongresi Bildiri Özetleri; 22-24 Eylül 2005; İzmir. p. 255.

34. Kendrick D, Smith S, Sutton A, Watson M, Coupland C, Mulvaney C, Mason-Jones A. Effect of education and safety equipment on poisoning-prevention practices and poisoning: systematic review, meta-analysis and metaregression. Arch Dis Child. 2008;93(7):599-608. doi: 10.1136/adc. 2007.133686 